\title{
Micro-Reactor Device For Dbsa-catalyzed Biodiesel Synthesis from Microalgae Chlorella Sp.
}

\author{
Ali A. Jazie ${ }^{1, *}$ Mustafa Jawad Nuhma ${ }^{1,3}$, Hassan Abdulkadhim Abbas ${ }^{2}$, Hajar Alias ${ }^{3}$ \\ ${ }^{1}$ Department of Chemical Engineering, University of Al-Qadisiyah, Al-Qadisiyah, Al-Diwaniyah, Iraq \\ ${ }^{2}$ Department of Mechanical Engineering, University of Al-Qadisiyah, Al-Qadisiyah, Al-Diwaniyah, Iraq \\ ${ }^{3}$ Department of Chemical Engineering, Faculty of Chemical and Natural Resources Engineering, Universiti \\ Teknologi Malaysia, 81310 Skudai, Johor
}

\begin{abstract}
The micro-reactor device was fabricated from Teflon and tested as a tool for biodiesel synthesis process from micro algae using Dodecylbenzenesulfonic acid catalyst. The variables influenceing on the biodiesel yield were optimized. The maximum yield of biodiesel of $99 \%$ was obtained at the reaction conditions of (temperature: $373.15 \mathrm{~K}$, residence time: $20 \mathrm{~min}$, methanol/oil ratio: 20, co-solvent amount: $30 \mathrm{wt} \%$ and catalyst amount: $11 \mathrm{wt} \%$ ). The influence of water content also investigated and recommended to be less than $0.5 \mathrm{wt} \%$. The acid value also reduced to a value of less than $0.5 \%$ at the optimum reaction condition. DBSA was found highly active catalyst for the esterification and transesterification reaction in the micro - reactor device. Biodiesel was produced in micro- reactor device at a small residence time $(20 \mathrm{~min})$ compared to the very long time consumed by the conventional batch process. Isopropanol was used as a co-solvent in the process and showed highly active in the biodiesel production.
\end{abstract}

\section{Introduction}

Currently, the biodiesel production needs to be enhanced to overcome the technical and ecological problems of long time consumption, low productivity, high energy consumption and mass transfer limitation associated with the conventional processes. Many research concentrated on the improvement the process towards a sustainable process for biodiesel synthesis [1-3]. Micro-reactors, are considered efficient technology for biodiesel synthesis and need to be intensified due to the lower residence time consumed by the process. Physically, the dispersion of the oil and alcohol in the micro-reactor would be increased and solve the problem of transport phenomena (mass and heat transfer) limitation in the conventional route [4-5]. Micro-reactor devices can be used industrially simply by stacking a number of microreactors for the commercial production [6-7]. The intensification of the micro-reactors has two main research divisions. The chemical intensification which concentrated on the investigation of the unusual reaction parameters [8-9] and process design intensification that search for a new and simple design [10-11]. Microtube reactor had been tested for the transesterification of palm oil and the influence of catalyst concentration and residence time were investigated for two different tube internal diameters [12]. The flow characteristics had been investigated in a milli-channel reactor used of the transesterification of a mixture of castor and sunflower oil [13]. In an experimental and simulation study, the biodiesel synthesis from sunflower oil in a microreactor was investigated for the operating conditions and compared the performance of microdevice with the batch reactor [14]. Recently, biodiesel had been produced in a $\mathrm{CaO}$ packed-microchaneel and enhanced by using Isopropanol co-solvent. The reactor conditions were optimized using the BBD (Box- Behnken design) with the RSM (response surface methodology) approach [15]. The objective of the present work is to design a microreactor fabricated from teflon for the biodiesel synthesis from microalgae Chlorella sp. oil. Dodecylbenzenesulfonic acid had been used as a catalyst for both the transesterification and esterification reactions and isopropanol was used as a co-solvent in the process. The variables affecting the biodiesel yield methanol/oil ratio, catalyst concentration, co-solvent concentration, reaction temperature, residence time, and water content were investigated and optimized.

\section{Experimental}

\subsection{Materials and measuring}

Dodecylbenzenesulfonic acid $(>0.99)$ was procured from Shanghai Hanhong Scientific Co., Ltd. Anhydrous MgSO4 (99.8 wt. \%), chloroform (99.8), methanol (99.9\%), isopropanol $(96 \%)$, hexane $(98.8 \%)$ and gas chromatography (GC) standard methyl heptadecanoate for the quantitative analysis of FAME were provided

Corresponding author: Ali.Jazie@qu.edu.iq 
from Sigma-Aldrech. All the chemical materials used were analytical reagents. Chlorella sp. extract was supplied from Shaanxi Jintai Biological Engineering Co., Ltd. The microalgae are dried at $343.15 \mathrm{~K}$. The independent examination of fatty acids shows that the lipid consists primarily from C16:0, C18:3, C18:2, C16:3, $\mathrm{C} 16: 2$, and $\mathrm{C} 18: 0$. The analysis of biodiesel produced at the optimum conditions for the free fatty acid profile and quantification are done using GC-2010-flame ionization detector (Shimadzu, Japan) armed with a split-splitless injector (oven temperature of $483.15 \mathrm{~K}$, injection volume $=2 \mu \mathrm{L}$, split injection temperature of $513.15 \mathrm{~K}$, split ratio $=1: 50$, flow rate $=1 \mathrm{ml} / \mathrm{min}$, column specification of $30 \mathrm{~m}$ length, $0.25 \mathrm{~mm}$ inside diameter.-0.25 thickness of film, analysis time of $30 \mathrm{~min}$ and detector temperature of $523.15 \mathrm{~K}$. Water content in microalgae sample was tested with the Karl Fischer tester (KF-1A). The acid value $(\mathrm{mg} \mathrm{KOH} / \mathrm{g})$ of the oil extracted from microalgae was measured using the standard titration method according with the approved method of American Oil Chemists Society (AOCS). Each test was conducted in triplicate.

\subsection{Extraction of oil}

Extraction of oil was done in a Soxhlet extraction by adding $50 \mathrm{~g}$ of dry Chlorella sp. into the upper part of the system with $150 \mathrm{ml}$ of (chloroform / methanol) as a solvent mixture and conducted at $338 \mathrm{~K}$ under magnetic stirring of 600 RPM in a $250-\mathrm{mL}$ round-bottom flask for a period of $3.5 \mathrm{hr}$. The resulted mixture then was filtered, evaporated and finally dried at $338 \mathrm{~K}$. the detailed extraction process was accoeding to Yuvarani et al., 2017 [16].

\subsection{Transesterification and esterification in a Micro-reactor}

Continuous transesterification and esterification of micro algae was conducted in a micro-reactor (internal tube diameter $=0.5 \mathrm{~mm}$, tube length $=500 \mathrm{~mm}$, number of tube $=100$ tubes). The reactor temperature was kept under constant temperature using a water bath at normal pressure. The schematic diagram and photograph of the micro-reactor device are shown in figure 1. Methanol was mixed with a suitable amount of DBSA as a catalyst. Catalyst- methanol mixture and Chlorella sp. oil was charged into the system using a glass syringe pumps. The parameters had been studied in the micro-reactor were as follows: reaction temperature (303.15 to 413.15 $\mathrm{K}$ ), methanol/oil ratio ( 5 to 50 ), residence time (5 to 30 min), catalyst amount (1-15 wt \%), co-solvent amount (0$35 \mathrm{wt} \%)$, and water content $(0.5-6 \mathrm{wt} \%)$. The different parameter was investigated and the experiments were repeated in triplicate (standard deviation was less than $5 \%$ for any point). Afterwards, for purifying the biodiesel product, excess alcohol was evaporated using rotary evaporator and hexane was added. Finally, The mixture was vacuum filtrated and the filtrate was dried over anhydrous MgSO4. GC-FID was used for the characterization of the product obtained from the packed bed reactor system. The tests were conducted in triplicate. The yield of microalgae biodiesel was calculated according to the following equation:

Biodiesel Yield (wt. \%) $=\frac{W_{b}}{W_{t}} \times 100=\frac{C F_{b}}{C F_{s}} \frac{A_{b}}{A_{s}} \frac{W_{s}}{W_{t}} \cdots$

Where $\mathrm{Wb}, \mathrm{Wt}, \mathrm{Ws}$, are the mass of biodiesel, total sample, and internal standard added to the sample, respectively, Ab, As is the peak area of biodiesel, and internal standard, respectively, $\mathrm{CFb}, \mathrm{CFs}$ is the correction factor of biodiesel, and internal standards.

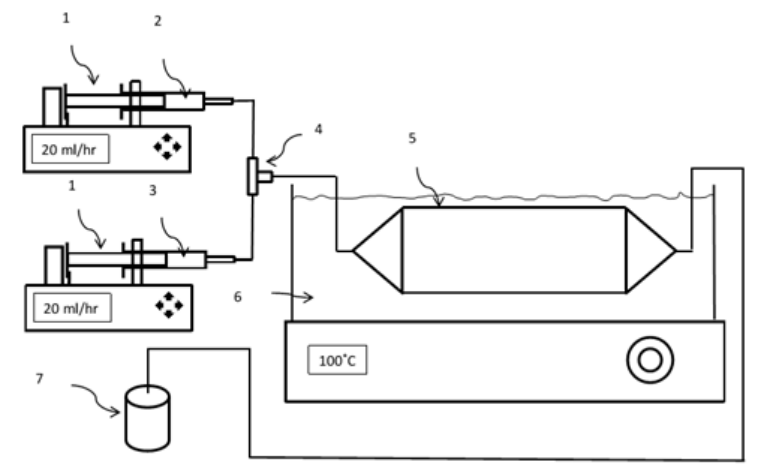

Fig. 1. Schematic diagram of the micro-reactor device set-up: 1Syringe pump; 2- Methanol and catalyst mixture; 3Microalgae oil; 4- T- shaped mixer; 5- Micro-reactor device; 6Water bath with thermostat; 7- Biodiesel product.

\section{Results and discussion}

\subsection{Influence of methanol/oil}

Figure 2a shows the effect of methanol/oil molar ratio at the reaction conditions of (reaction temperature: 373.15 $\mathrm{K}$, residence time: $20 \mathrm{~min}$, co-solvent: $30 \mathrm{wt} \%$, and catalyst amount: $5 \mathrm{wt} \%$ and $9 \mathrm{wt} \%$ ). Biodiesel yield in figure $2 \mathrm{a}$ shows an a rise as the methanol/oil molar ratio increased from 5 to 20 molar ratio. The reason beyond that increase can be as a result of the favor the forward direction in the transesterification reaction. The same result was observed by other researchers [17]. Then, a slight decrease was observed in the biodiesel yield, which may be due to the remaining portion of the biodiesel in the glycerol phase and can not be separated. Mansourpoor and Shariat also observed the same behavior [18]. Figure 2a shows that the biodiesel yield at a catalyst amount of $9 \mathrm{wt} \%$ (biodiesel yield=99\%) was higher than that one at a $5 \mathrm{wt} \%$ (only $60 \%$ ). Effect of methanol/oil molar ratio on the acid value was shown in figure $2 \mathrm{~b}$. The acid value was reduced due to the increasing the methanol/oil ratio and showed an acid value of less than $0.5 \%$ at a methanol/oil ratio of 20 . Catalyst ratio of $9 \mathrm{wt} \%$ was found to be the optimum ratio for decreasing the acid value due to the changing the FFA (free fatty acids) in the microalgae oil. Afterward, It was observed that there is a slight increase in the acid value due to the dilution of DBSA catalyst and this is agree with a previous study [19]. 


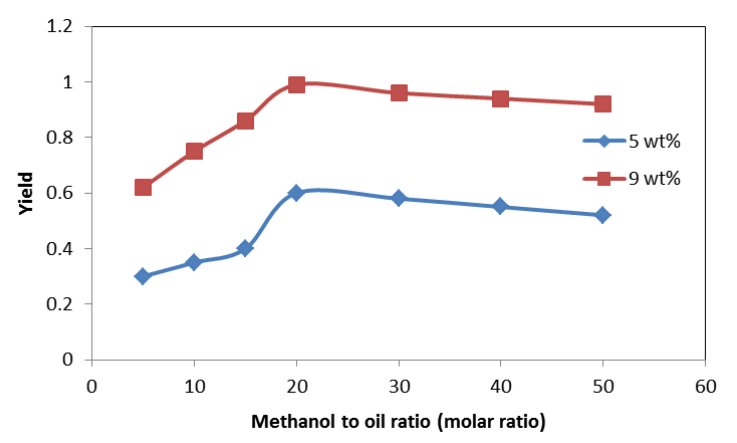

Fig. 2.a Influence of methanol/oil ratio on biodiesel yield: reaction temperature $373.15 \mathrm{~K}$; residence time $20 \mathrm{~min}$; cosolvent $30 \mathrm{wt}$; catalyst to oil 5 and $9 \mathrm{wt} \%$.

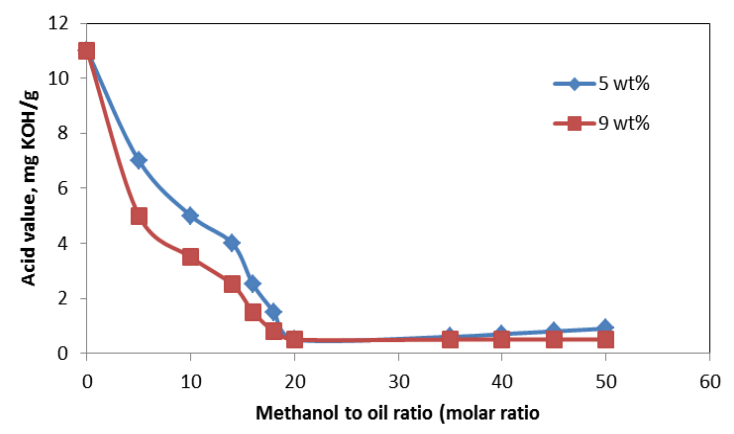

Fig. 2.b Influence of methanol/oil ratio on acid value: reaction temperature $373.15 \mathrm{~K}$; residence time $20 \mathrm{~min}$; co-solvent: 30 wt $\%$; catalyst to oil 5 and $9 \mathrm{wt} \%$.

\subsection{Influence of catalyst amount}

The influence of catalyst concentration on the biodiesel yield was investigated as shown in the figure 3a. The reaction conditions were (reaction temperature: 338.15 ; 358.15; and $373.15 \mathrm{~K}$, methanol/oil ratio: 20 , residence time: $20 \mathrm{~min}$, and co-solvent: $30 \mathrm{wt} \%$ ). Catalyst concentration was varied in the range of $1-15 \mathrm{wt} \%$. Figure 3a shows a rise in the biodiesel yield with changing temperature from 338.15 to $373.15 \mathrm{~K}$. Moreover, biodiesel yield improved with increasing the catalyst amount until reaching the maximum value of $99 \%$ at the catalyst amount of $9 \mathrm{wt} \%$ and a temperature of $373.15 \mathrm{~K}$. A slight decrease in biodiesel yield was observed when increasing the catalyst amount beyond the value of $9 \mathrm{wt} \%$ due to the carbonization in the presence of DBSA as stated by other researchers also using an acid catalyst [20-21].

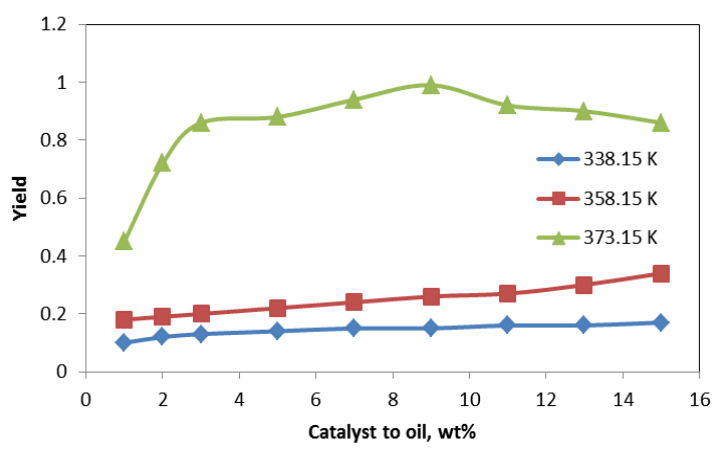

Fig. 3.a Influence of catalyst to oil ratio on biodiesel yield: residence time $20 \mathrm{~min}$; methanol/oil ratio 20; co-solvent 30 wt $\%$, reaction temperature $338.15,358.15$, and $373.15 \mathrm{~K}$.

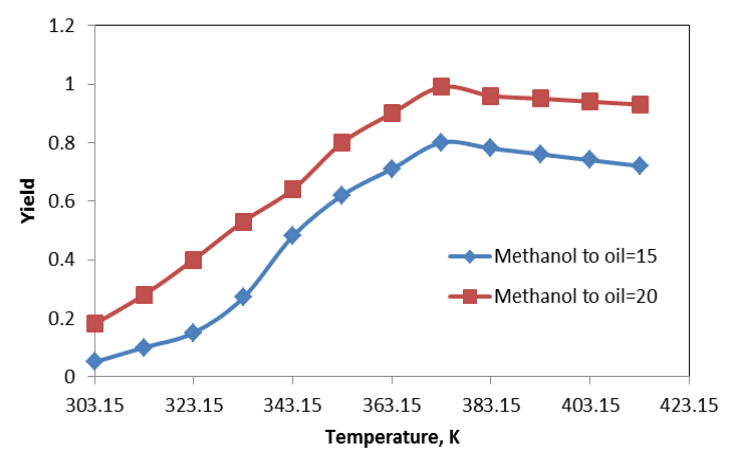

Fig. 3.b Influence of reaction temperature on biodiesel yield: residence time $20 \mathrm{~min}$; catalyst to oil $9 \mathrm{wt} \%$; co-solvent $30 \mathrm{wt} \%$; methanol/oil ratio 15 and 20.

\subsection{Influence of reaction temperature}

Figure 5 shows the effect of reaction temperature on the biodiesel yield at variables (catalyst amount: $9 \mathrm{wt} \%$, methanol/oil ratio: 15 and 20, residence time of $20 \mathrm{~min}$, and range of temperature: 303.15-413.15 K). The increase of temperature would increase the kinetic energy of the reacted molecules and led to that increase in the biodiesel yield until reaching the temperature of $373.15 \mathrm{~K}$. Afterward, further increase of temperature showed a slight decrease in biodiesel yield due to the miscibility of biodiesel product in the glycerol by-product.

\subsection{Influence of residence time}

The influence of the reaction time on the biodiesel yield was shown in the figure 4a. The reaction conditions for the experiments were (catalyst amount: $9 \mathrm{wt} \%$, methanol/oil ratio: 15 and 20, co-solvent: $30 \mathrm{wt} \%$, reaction temperature: $373.15 \mathrm{~K}$, and range of residence time of 5-50 $\mathrm{min}$ ). As stated by other researchers [22-23] and agree with the present study, the biodiesel yield 
increase with increasing the residence time. The maximum biodiesel yield of $80 \%, 99 \%$ were obtained at a residence time of $20 \mathrm{~min}$ in the micro-reactor using a methanol/oil molar ratio of 15 , and 20 respectively. Beyond the residence time of $20 \mathrm{~min}$, a slight decrease in the biodiesel yield was observed and can be deduced to the increase of di and mono glyceride molecules by the reversible transesterification reaction which agree with the results of Encinar et al., (2016) [24]. A shorter residence time was consumed by the micro-reactor in the present study compared to the conventional batch process make a sense to use it industrially.

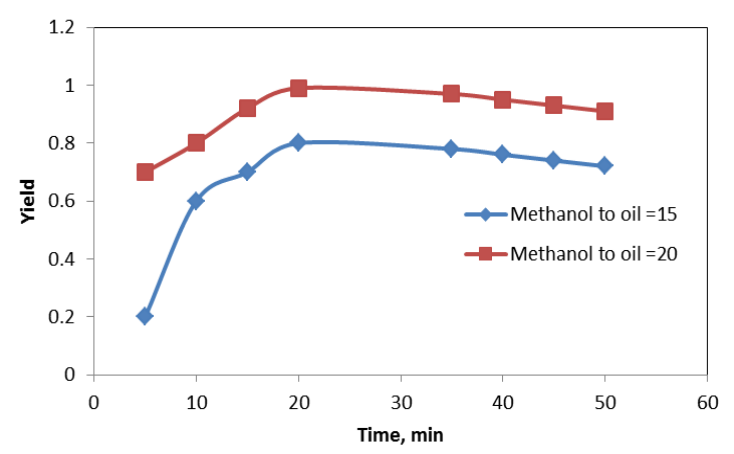

Fig. 4.a Influence of residence time on biodiesel yield: reaction temperature $373.15 \mathrm{~K}$; catalyst to oil $9 \mathrm{wt} \%$; co-solvent $30 \mathrm{wt} \%$; methanol/oil ratio 15 and 20 .

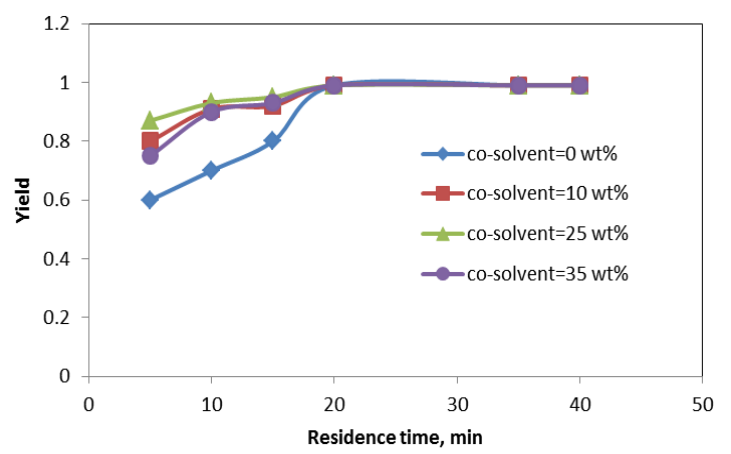

Fig. 4.b Influence of co-solvent on biodiesel yield: reaction temperature $373.15 \mathrm{~K}$; catalyst to oil $9 \mathrm{wt} \%$; methanol/oil ratio 20; residence time $20 \mathrm{~min}$.

\subsection{Influence of co-solvent}

Figure $4 \mathrm{~b}$ shows the influence of co-solvent on the yield of biodiesel. Isopropanol was selected as a co-solvent due to the very low reactivity of it towards the transesterification reaction based on the literature reports [25]. A primary experiment was conducted at the reaction conditions of (methanol/oil ratio: 20, catalyst amount: 9 $\mathrm{wt} \%$, residence time: $20 \mathrm{~min}$, and a reaction temperature: $373.15 \mathrm{~K}$ ) for the clarification regarding the reactivity of isopropanol in the transesterification reaction. Then, at the same conditions mentioned above, the biodiesel yield was studied in the range of co-solvent amount influence between $10-35$ weight $\%$. Figure $4 b$ shows an enhance in the biodiesel yield with increasing the co-solvent ratio at an appropriate residence time and this phenomena attributed to the increase the dispersion of oil-methanol system and interface mass transfer rate [26]. Isopropanol was found an influenceive co-solvent in the transesterification reaction of microalgae.

\subsection{Influence of water content}

The water content had a negative influence on the biodiesel yield as shown in the figure 5 . The experiments were conducted at the reaction conditions of (methanol/oil ratio: 20, catalyst amount: $9 \mathrm{wt} \%$, residence time: $20 \mathrm{~min}$, co-solvent: $30 \mathrm{wt} \%$ and a reaction temperature: $373.15 \mathrm{~K})$. By adding $1-8 \%$ of a distilled water to the microalgae oil and conducting the reaction, was found that the maximum value of accepted water content in the microalgae oil must be less than $0.5 \%$. The present results agree with the literature [27].

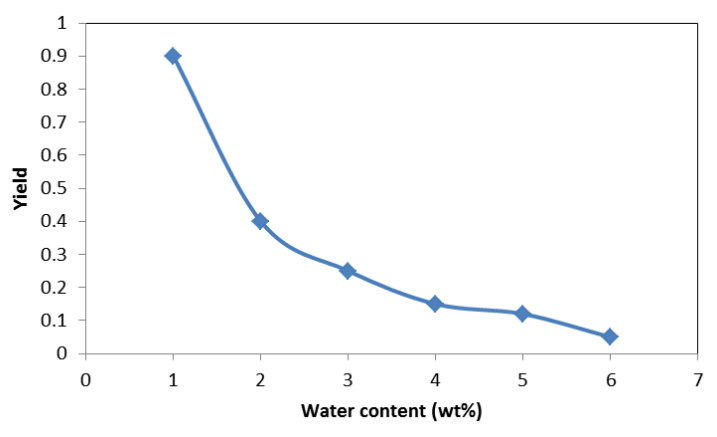

Fig. 5 Influence of water content on biodiesel yield: reaction temperature $373.15 \mathrm{~K}$; catalyst to oil $9 \mathrm{wt} \%$; co-solvent $30 \%$; methanol/oil ratio 20; residence time $20 \mathrm{~min}$.

\section{Conclusion}

The esterification and transesterification reactions of microalgae oil using DBSA catalyst were investigated in the micro-reactor device. The device showed high activity for the production of biodiesel in a short residence time. Also, the catalyst DBSA was a found to be a suitable catalyst for the reactions due to the hydrophobicity which can reduce the high content of FFA (free fatty acids) in the microalga oil. The optimum reaction conditions were found as follows: reaction temperature $373.15 \mathrm{~K}$, residence time $20 \mathrm{~min}$, methanol/oil ratio 20, co-solvent $30 \mathrm{wt} \%$, and catalyst amount 9 wt \%. The water content value of less than $0.5 \%$ was proved of negligible influence on the biodiesel yield. The present study, recommend the use of a stacked micro-reactor industrially for the production of biodiesel from microalgae using DBSA which would be an efficient economic process compared to the batch process.

\section{Acknowledgments}

Author would lick to thank the staff of the department of chemical engineering/ College of Engineering/ University of Al Qadisiyah for providing the laboratory assistant facility. 


\section{References}

1. Jazie, A. A., Abed, S. A., Nuhma, M. J., \& Mutar, M. A. (2019). Continuous biodiesel production in a packed bed reactor from microalgae Chlorella sp. using DBSA catalyst. Engineering Science and Technology, an International Journal.

2. Jazie, A. A. (2019). DBSA-Catalyzed Sewage Sludge Conversion into Biodiesel in a CSTR: RSM Optimization and RTD Study. Journal of Engineering \& Technological Sciences, 51(4)

3. Jazie, A. A., Alshebaney, E. J., \& Abed, S. A. (2019, August). In-Situ Dodecylbenzenesulfonic acidCatalyzed Transesterification of Micro Algae Chlorella Sp. for Biodiesel Production. In 2019 International Conference on Power Generation Systems and Renewable Energy Technologies (PGSRET) (pp. 1-6). IEEE.

4. Kumar, V., and Nigam, K. D. P. 2012. Process intensification in green synthesis. Green Processing and Synthesis. 1:79-107.

5. Yeh, S. I., Huang, Y. C., Cheng, C. H., Cheng, C. M., \& Yang, J. T. (2016). Development of a millimetrically scaled biodiesel transesterification device that relies on droplet-based co-axial fluidics. Scientific reports, 6 .

6. Jazie, A. A., Abed, S. A., \& Pramanik, H. (2019, August). DBSA-Catalyzed Biodiesel Production From Sewage Sludge In A Micro-Reactor: Box-Behnken Design Optimization. In 2019 International Conference on Power Generation Systems and Renewable Energy Technologies (PGSRET) (pp. 1-6). IEEE.

7. Qiu, Z., Zhao, L., and Weatherley, L. 2010. Process intensification technologies in continuous biodiesel production. Chemical Engineering and Processing: Process Intensification. 49:323-330.

8. Hessel, V., Vural Gürsel, I., Wang, Q., Noel, T., and Lang, J. 2012. Potential analysis of smart flow processing and micro process technology for fastening process development: use of chemistry and process design as intensification fields. Chemical Engineering \& Technology. 35:1184-1204.

9. Budžaki, S., Miljić, G., Tišma, M., Sundaram, S., and Hessel, V. 2017. Is there a future for enzymatic biodiesel industrial production in microreactors?. Applied Energy. 201:124-134.

10. Fischmeister, C., and Doucet, H. 2011. Greener solvents for ruthenium and palladium-catalysed aromatic $\mathrm{C}-\mathrm{H}$ bond functionalisation. Green Chemistry. 13:741-753.

11. Wegner, J., Ceylan, S., \& Kirschning, A. (2011). Ten key issues in modern flow chemistry. Chemical Communications, 47(16), 4583-4592.

12. Azam, N. A. M., Uemura, Y., Kusakabe, K., and Bustam, M. A. 2016. Biodiesel Production from Palm Oil Using Micro Tube Reactors: Influences of Catalyst Concentration and Residence Time. Procedia Engineering. 148:354-360.

13. Jamil, M. F., Uemura, Y., Kusakabe, K., Ayodele, O. B., Osman, N., Ab Majid, N. M. N., and Yusup, S. 2016. Transesterification of Mixture of Castor Oil and Sunflower Oil in Millichannel Reactor: FAME Yield and Flow Behaviour. Procedia Engineering. 148:378384.
14. Santana, H. S., Tortola, D. S., Reis, É. M., Silva, J. L., and Taranto, O. P. 2016. Transesterification reaction of sunflower oil and ethanol for biodiesel synthesis in microchannel reactor: Experimental and simulation studies. Chemical Engineering Journal. 302:752-762.

15. Chueluecha, N., Kaewchada, A., and Jaree, A. 2017. Enhancement of biodiesel synthesis using co-solvent in a packed-microchannel. Journal of Industrial and Engineering Chemistry. 51:162-171.

16. Yuvarani, M., Kubendran, D., Salma Aathika, A. R., Karthik, P., Premkumar, M. P., Karthikeyan, V., \& Sivanesan, S. (2017). Extraction and characterization of oil from macroalgae Cladophora glomerata. Energy Sources, Part A: Recovery, Utilization, and Environmental Effects, 1-7.F. De Lillo, F. Cecconi, G. Lacorata, A. Vulpiani, EPL, 84 (2008).

17. Oyelade, J. O., Idowu, D. O., Oniya, O. O., and Ogunkunle, O.2017. Optimization of biodiesel production from sandbox (Hura crepitans L.) seed oil using two different catalysts. Energy Sources, Part A: Recovery, Utilization, and Environmental Effects. 39: 1242-1249.

18. Mansourpoor, M., and Shariati, A. 2012. Optimization of biodiesel production from sunflower oil using response surface methodology. J Chem Eng Process Technol. 3:4

19. Yao, J., Ji, L., Sun, P., Zhang, L., \& Xu, N. (2010). Low boiling point organic amine-catalyzed transesterification of cottonseed oil to biodiesel with trace amount of $\mathrm{KOH}$ as co-catalyst. Fuel, 89(12), 3871-3875.

20. Cao, F., Chen, Y., Zhai, F., Li, J., Wang, J., Wang, $\mathrm{X}$., ... and Zhu, W. 2008. Biodiesel production from high acid value waste frying oil catalyzed by superacid heteropolyacid. Biotechnology and bioengineering. 101:93-100.

21. Miao, X., Li, R., and Yao, H. 2009. Influenceive acidcatalyzed transesterification for biodiesel production. Energy Conversion and Management. 50:2680-2684.

22. Ab Rashid, W., Norita, W., Uemura, Y., Kusakabe, K., Osman, N. B., and Abdullah, B. 2014. Biodiesel Production from Palm Oil in a Millichannel Reactor. In Applied Mechanics and Materials. 465:232-236.

23. Rahimi, M., Aghel, B., Alitabar, M., Sepahvand, A., and Ghasempour, H. R. 2014. Optimization of biodiesel production from soybean oil in a microreactor. Energy Conversion and Management. 79:599-605.

24. Encinar, J. M., Pardal, A., and Sánchez, N. 2016. An improvement to the transesterification process by the use of co-solvents to produce biodiesel. Fuel. 166:5158 .

25. Wu, L., Huang, K., Wei, T., Lin, Z., Zou, Y., \& Tong, Z. (2016). Process intensification of $\mathrm{NaOH}$-catalyzed transesterification for biodiesel production by the use of bentonite and co-solvent (diethyl ether). Fuel, 186, 597-604.

26. Lam, M. K., and Lee, K. T. 2010. Accelerating transesterification reaction with biodiesel as cosolvent: A case study for solid acid sulfated tin oxide catalyst. Fuel. 89:3866-3870.

27. Kusdiana, D., and Saka, S. 2004. Influences of water on biodiesel fuel production by supercritical methanol treatment. Bioresource technology. 91:289-295. 